\title{
Effect of Lauroyl Glutamine on Biodegradation of Lubricating Oil and Simulation of Biodegradation Kinetics
}

\author{
Boshui Chen $^{1 *}$, Jiang Wu ${ }^{1}$, Jianhua Fang ${ }^{1}$, Weijiu Huang ${ }^{2}$, Jiu Wang ${ }^{1}$ \\ ${ }^{1}$ College of Petrochemistry, Logistical Engineering University, Chongqing, China \\ ${ }^{2}$ College of Material Engineering, Chongqing University of Science and Technology, Chongqing, China \\ E-mail: chenboshui@yahoo.com.cn \\ Received July 29, 2010; revised October 8, 2010; accepted October 12, 2010
}

\begin{abstract}
Small amount of lauroyl glutamine was incorporated into HVI 350 mineral lubricating oil and the biodegradabilities of neat oil and the formulated oil in soils were evaluated. Thereafter, the biodegradation rate equations for the two lubricating oils were simulated based on the exponential model. The results indicated that lauroyl glutamine effectively promoted biodegradation of HVI 350 mineral lubricating oil. Under given test conditions, the exponential model well fitted the biodegradation of lubricating oils in soils. The biodegradation rate equation for HVI 350 mineral lubricating oil can be described as $\ln \left(S_{t} / S_{0}\right)=-0.0155 t$, while that for the oil formulated with lauroyl glutamine as $\ln \left(S_{t} / S_{0}\right)=-0.0235 t$. The biodegradation half-lives of neat oil and the formulated oils were 44.72 days and 29.50 days, respectively.
\end{abstract}

Keywords: Lauroyl Glutamine, Lubricating Oil, Biodegradation, Kinetics

\section{Introduction}

It has been known that environmental pollution caused by petroleum-based lubricants is severe due to their inherent toxicity and non-biodegradable nature [1]. During the last decades, the increased public attention and the awareness of protection of the environment have stimulated the development of lubricants that show more or less compatibility with the environment, and environmental compliance of lubricants has become a topic of interested research [2-6]. The ecologically responsive technology and lubricant design seek to meet both performance and environmental needs, to harmonize the technical performance and the ecological requirements. The key issue in formulating biodegradable lubricants is the choice of reliable base oils and suitable performance additives. Nowadays, many base fluids such as vegetable oils and synthetic esters have found practical applications in the formulation of biodegradable lubricants because of their excellent biodegradability and non-toxicity [7-9]. On the other hand, the development of alternatives to conventional lubricant additives such as ZDDP has also been a subject of significant interest, mainly due to environmental concerns arising from S, P and metal atoms of the additives [10]. As we know, petroleum-based lubricants, which consist predominantly of hydrocarbons and subsidiarily of additives which are often environmentally hazardous, are the most commonly used lubricants of today and will presumably continue to play their important roles in the future lubrication applications. Even though choice of mineral base oils in biodegradable lubricant formulations has as far never been recommended, improvement of their environmental safety such as better biodegradability and development of greener additives are indeed indispensable.

Many amino acids have been known to be ready biodegradable and low eco-toxic, and have been described as being environmentally friendly. Amino acids such as lauroyl glutamine are known to be nutriments for microbes and, if incorporated into an unreadily biodegradable lubricant, are expected to be capable of promoting microbial production and increasing microbial populations, thus improving biodegradability of the lubricant. Furthermore, lauroyl glutamine is a bio-surfactant. As a lubricant additive, it may adsorb on or react with tribomates to act as a friction and wear reducer, fortifying anti-wear and friction-reducing abilities of the lubricants in the tribological processes as a result [11]. In the present paper, the effect of lauroyl glutamine on biodegradation of a mineral lubricating oil was reported. The biodegradation kinetics of lubricating oils in soils was also preliminarily studied. 


\section{Experimentals}

\subsection{Materials}

HVI 350 mineral lubricating oil: A well refined petroleum-based paraffinic lubricating oil whose kinematic viscosity at $40^{\circ} \mathrm{C}$ is $98.16 \mathrm{~mm}^{2} / \mathrm{s}$.

Lauroyl glutamine (named as L-Glu): A readily biodegradable amino acid prepared by the authors.

Soil specimen: Obtained from under the earth's surface of about 15 centimeters and screened out with a sizer $1 \mathrm{~mm}$ in pore diameter.

\subsection{Biodegradation Test}

For evaluating the effect of lauroyl glutamine on biodegradation of mineral lubricating oils, $0.5 \%$ mass percent of lauroyl glutamine was incorporated into HVI 350 mineral lubricating oil. Thereafter, a certain amount of the neat oil and the lauroyl glutamine-doped oil were well blended with the soil specimens, respectively. The soils with the neat oil and with the formulated oil were then ready for biodegradation tests. In the present study, three specimens for both the neat oil and the formulated oil in soils were prepared, respectively, for parallel biodegradation tests. The biodegradation tests for the total six oil-containing soil specimens were conducted simultaneously at room temperatures under the simulated environmental conditions by continuously pumping air into the soils at the rate of about $15 \mathrm{~L} / \mathrm{min}$. while keeping water contents of the soils at about $25 \%$.

After certain biodegradation durations, viz. 0 day, 2 days, 5 days, 10 days, 15 days and 20 days, the total residual concentrations of oils in soils were determined and the biodegradability of the neat oil and the formulated oil in each soil specimen after each duration was calculated by the equation given bellow:

$$
\varepsilon_{t}=\frac{S_{0}-S_{t}}{S_{0}} \times 100 \%
$$

where $\varepsilon_{t}$ is the biodegradability of an oil at time $t ; S_{0}$ is the initial concentrations of an oil in soil $\left(\mathrm{mg} \cdot \mathrm{g}^{-1}\right) ; S_{t}$ is the residual concentrations of an oil in soil after $t$ days of biodegradation $\left(\mathrm{mg} \cdot \mathrm{g}^{-1}\right)$. The detailed procedures for determining residual oil concentrations after $t$ days of biodegradation are as follows.

For each oil-containing soil specimen, a 10-gram soil sample was taken out and put into an Erlenmeyer flask with stopper. Then, $50 \mathrm{~mL}$ of chloroform $\left(\mathrm{CHCl}_{3}\right)$ as an extracting agent were added into the soil sample with mild stirring and the flask was then allowed to stand overnight. Thereafter, the flask was heated in a water bath of $50 \sim 55^{\circ} \mathrm{C}$ for about 1hour, and the extractant was then pump-filtered into an accurately weighed beaker. The soil residue was further extracted with $25 \mathrm{~mL}$ of $\mathrm{CHCl}_{3}$ twice following the likewise procedures and the extractant was filtered into the beaker along with the others. After extraction, the beaker was heated in a water bath of $50 \sim 55^{\circ} \mathrm{C}$ in a ventilating hood to remove $\mathrm{CHCl}_{3}$, and then dried in an oven of $60 \sim 75^{\circ} \mathrm{C}$ for 4 hours. After cooling to room temperatures, the beaker was again accurately weighed. The weight increase of the beaker was consequently the amount of the total residual oil in the soil sample. Therefore, $S_{t}$, the residual concentrations of an oil in soil after $t$ days of biodegradation, was obtained by dividing the amount of the residual oil with the amount of the soil sample. The average values of $S_{t}$ for both the neat oil and the formulated oil were reported in this paper.

\section{Results and Discussion}

\subsection{Effect of Lauroyl Glutamine on Biodegradability of Lubricating Oil}

Table 1 shows the variation of the residual concentrations of oil in soil and the biodegradability of lubricating oils with durations.

It can be seen from Table 1 that, after each tested duration, viz. 2 days, 5 days, 10 days, 15 days and 20 days, the total residual concentrations of the oil formulated with lauroyl glutamine were much lower than those of the neat oil in soils. This indicated that lauroyl glutamine acted as a biodegradation accelerant and thus effectively enhanced biodegradability of HVI 350 mineral lubricating oil.

As we know, biodegradability is not an exact property or characteristic of a substance, but is also a system's concept, i.e. a system with its conditions determines whether or not a substance within it is biodegraded. Studies have shown that many compounds such as phosphorous and nitrogenous ones, are highly effective in promoting hydrocarbons to biodegrade, and have been successfully employed in the bio-remediation of petroleum polluted areas such as water and soil [12-14]. Promotion of biodegradation of a mineral lubricating oil by

Table 1. Variation of residual concentrations of oil in soil and biodegradability of lubricating oils with durations.

\begin{tabular}{ccccc}
\hline \multirow{2}{*}{$t / \mathrm{d}$} & \multicolumn{2}{c}{ HVI 350} & \multicolumn{2}{c}{ HVI 350 + L-Glu } \\
\cline { 2 - 5 } & $S_{t} /{\mathrm{mg} \cdot \mathrm{g}^{-1}}^{2}$ & $\varepsilon_{t} / \%$ & $S_{t} /{\mathrm{mg} \cdot \mathrm{g}^{-1}}$ & $\varepsilon_{t} / \%$ \\
\hline 0 & 50.4 & & 51.2 & \\
2 & 49.1 & 2.58 & 46.2 & 9.77 \\
5 & 47.9 & 4.96 & 42.7 & 16.60 \\
10 & 44.6 & 11.51 & 39.6 & 22.66 \\
15 & 41.2 & 18.25 & 34.7 & 32.23 \\
20 & 37.2 & 26.19 & 29.9 & 41.60 \\
\hline
\end{tabular}


lauroyl glutamine is thus evidentially doable.

\subsection{Simulation of Biodegradation Kinetics}

It has been known that the biodegradation rate of many organic substances can be well fitted by the exponential model [15]. Therefore for biodegradation of lubricating oil in soil, the exponential function $S(t)=S(0) e^{-k t}$ satisfies the linear differential equation:

$$
\frac{d S}{d t}=-k S
$$

where $S$ is the oil concentration and $k$ is the biodegradation rate constant.

Saying that the biodegradation rate of $S$ at time $t$ is proportional to the value of $S_{t}$, and it has the initial value $S_{0}$, the differential equation is solved by the method of separation of variables:

$$
\frac{d S_{t}}{S_{t}}=-k d t
$$

Integration of the Equation (3) and incorporation of the initial value gives:

$$
\ln \left(\frac{S_{t}}{S_{0}}\right)=-k t
$$

Based on the Equation (4) and the biodegradation test results given in Table 1, the biodegradation kinetics of HVI 350 lubricating oil and the oil with lauroyl glutamine can be regressed. Table 2 shows the variations of the contents of lubricating oils in soils and the natural logarithms of $\frac{S_{t}}{S_{0}}$ with biodegradation durations.

Figure 1 and Figure 2 show the regression curves of biodegradation rate equation for HVI 350 lubricating oil and the oil with lauroyl glutamine, respectively.

It can be seen from Figure 1 and Figure 2 that the regression curves for biodegradation rates of both neat oil and the formulated oil are well linearized, as indicates that the biodegradation of lubricating oils in soils can be well simulated by the exponential model. The slopes of

Table 2. Variations of contents of lubricating oils in soils and $\ln \left(S_{t} / S_{0}\right)$ with durations.

\begin{tabular}{ccccc}
\hline & \multicolumn{2}{c}{ HVI 350} & \multicolumn{2}{c}{ HVI $350+$ L-Glu } \\
\cline { 2 - 5 }$t / \mathrm{d}$ & & & \\
& $S_{t} / \mathrm{mg}^{-1}$ & $\ln \left(\frac{S_{t}}{S_{0}}\right)$ & $S_{t} / \mathrm{mg}^{-1} \mathrm{~g}^{-1}$ & $\ln \left(\frac{S_{t}}{S_{0}}\right)$ \\
\hline 0 & 50.4 & & 51.2 & \\
2 & 49.1 & -0.0261 & 46.2 & -0.1028 \\
5 & 47.9 & -0.0509 & 42.7 & -0.1815 \\
10 & 44.6 & -0.1223 & 39.6 & -0.2569 \\
15 & 41.2 & -0.2016 & 34.7 & -0.3890 \\
20 & 37.2 & -0.3037 & 29.9 & -0.5379 \\
\hline
\end{tabular}

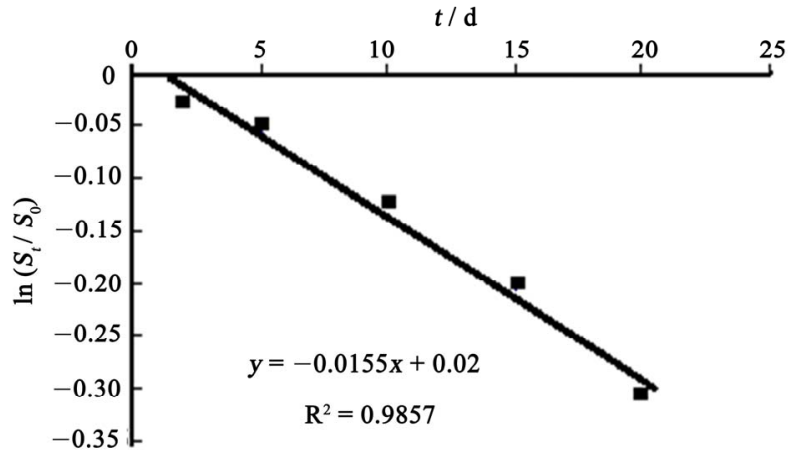

Figure 1. Regression curve of biodegradation rate equation for HVI 350.

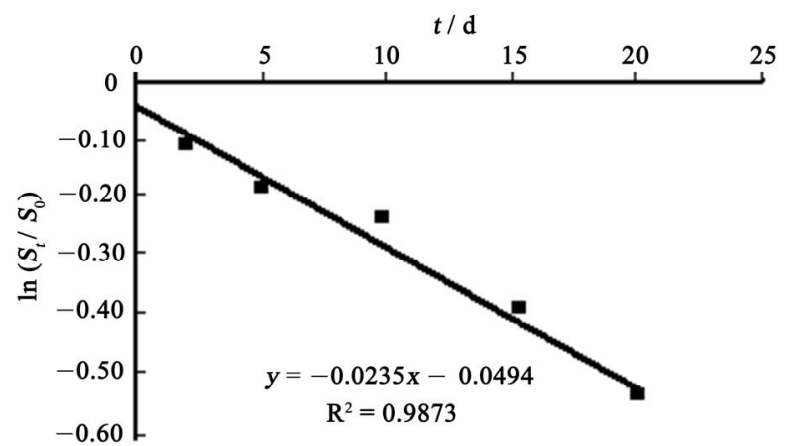

Figure 2. Regression curve of biodegradation rate equation for HVI 350 with lauroyl glutamine.

the regression lines, which correspond to the biodegradation rate constants, $k$, are $0.0155 \mathrm{mg} \cdot \mathrm{g}^{-1} \cdot \mathrm{d}^{-1}$ for HVI 350 lubricating oil and $0.0235 \mathrm{mg} \cdot \mathrm{g}^{-1} \cdot \mathrm{d}^{-1}$ for the formulated oil, respectively. Therefore, the biodegradation rate equations for neat oil and the formulated oil can be obtained as given in Equations (5) and (6), respectively.

$$
\begin{aligned}
& \ln \left(\frac{S_{t}}{S_{0}}\right)=-0.0155 t \\
& \ln \left(\frac{S_{t}}{S_{0}}\right)=-0.0235 t
\end{aligned}
$$

Based on the Equations (5) and (6), the biodegradation half-life, $t_{1 / 2}$, for neat oil and the formulated oil can also be calculated. In the present test, the half-life is numerically equal to $\frac{\ln 2}{k}$ and is 44.72 days for neat oil and 29.50 days for the formulated oil, respectively.

\section{Conclusions}

Based on the results given above, the following conclusions can be drawn.

Lauroyl glutamine as a green additive effectively accelerated biodegradation of non-biodegradable mineral 
lubricating oils such as HVI 350 oil. Under given test conditions, the biodegradation of HVI 350 lubricating oil and the oil formulated with lauroyl glutamine can be well simulated by the exponential model. The biodegradation kinetics for HVI 350 mineral lubricating oil can be expressed by the rate equation of $\ln \left(\frac{S_{t}}{S_{0}}\right)=-0.0155 t$, while that for the oil formulated with lauroyl glutamine by $\ln \left(\frac{S_{t}}{S_{0}}\right)=-0.0235 t$. The biodegradation half-lives of neat oil and the formulated oils were 44.72 days and 29.50 days, respectively.

\section{Acknowledgements}

The authors gratefully acknowledge the financial support of National Natural Science Foundation of China (project No.50975282) and Natural Science Foundation for Outstanding Youths, Chongqing, China (project No. CSTC, 2008BA4037).

\section{References}

[1] F. Haus, G. Jean and G. A. Junter, "Primary Biodegradability of Mineral Base Oils in Relation to Their Chemical and Physical Characteristics," Chemosphere, Vol. 45, No. 6, 2001, pp. 983-990.

[2] W. J. Bartz, "Environmentally Acceptable Tribological Practices," Proceedings of the 4th China International Symposium on Tribology, Xi'an, 8-11 November 2004, pp. 1-11.

[3] S. Boyde, "Green Lubricants: Environmental Benefits and Impacts on Lubrication," Green Chemistry, Vol. 12, No. 4, 2002, pp. 293-307.

[4] L. Havet, J. Blouet and F. R. Valloire, "Tribological Characteristics of Some Environmentally Friendly Lubricants,” Wear, Vol. 248, No. 1-2, 2001, pp. 140-146..
[5] A. Willing, "Lubricants Based on Renewable ResourcesAn Environmentally Compatible Alternative to Mineral Oil Products,” Chemosphere, Vol. 43, No. 1, 2001, pp. 89-98.

[6] G. Rebeccal and M. Rogere, "Biodegradable Lubricants," Lubrication Engineering, Vol. 7, 1998, pp. 10-16.

[7] Z. E. Sevim and A. Svajus, "Lubricant Basestocks from Vegetable Oils,” Industrial Crops and Products, Vol. 11, No. 2-3, 2000, pp. 277-282.

[8] N. J. Fox and G. W. Stachowiak, "Vegetable Oil-Based Lubricants-A Review of Oxidation,” Tribology International, Vol. 40, No. 7, 2007, pp. 1035-1046.

[9] S. J. Randles and M. Wright, "Environmentally Considerate Ester Lubricants for Automotive and Engineering Industries,” Journal of Synthetic Lubrication, Vol. 9, No. 2, 1992, pp. 145-161.

[10] S. H. Roby and J. A. Supp, "Formulating for ILSAC GF-2-Part 1: Obtaining Valve Train Wear Protection While Reducing the Phosphorus Content of a Motor Oil," Special Publication: Society of Automotive Engineers, SP-1121, 1995, pp. 23-27.

[11] X. Sun and B. S. Chen, "Tribological Behaviors of Lauroyl Glutamine as Additive in Lubricating Oils,” Lubrication Engineering, in Chinese, Vol. 32, No. 6, 2007, pp. 54-58.

[12] T. Sobisch and H. Niebelschutz, "Effect of Additives on Biodegradation of PAH in Soils," Colloids and Surfaces A: Physicochemical and Engineering Aspects, Vol. 162, No. 1, 2000, pp. 1-14.

[13] M. Molnar and L. Leitgib, "Enhanced Biodegradation of Transformer Oil in Soils with Cyclodextrin-from the Laboratory to the Field,” Biodegradation, Vol. 16, No. 2, 2005, pp. 159-168.

[14] X. Y. Li and D. Z. Wei, "Effect of Nitrogenous and Phosphorous Compounds on Degradation of Microbes,” Nonferrous Metals, in Chinese, Vol. 18, No. 4, 2000, pp. 237-239.

[15] D. Z. Shen, "Bio-Remediation of Polluted Environments," in Chinese, Chemical Industry Press, Beijing, 2002. 